\title{
Influence of hypothyroidism on circulating concentrations and liver expression of IGF-binding proteins mRNA from neonatal and adult rats
}

\author{
S Ramos, L Goya, M A Martín, F Escrivá and A M Pascual-Leone \\ Instituto de Bioquímica (Centro Mixto CSIC-UCM), Facultad de Farmacia, Ciudad Universitaria, 28040 Madrid, Spain \\ (Requests for offprints should be addressed to A M Pascual-Leone; Email: apascual@farm.ucm.es)
}

\begin{abstract}
The aim of this work was to study the influence of the endocrine balance between thyroid hormones, insulin and growth hormone $(\mathrm{GH})$ on the regulation of insulin-like growth factor binding proteins (IGFBPs), complementing a study previously reported for insulin-like growth factors (IGFs) in similar populations. Serum concentrations of IGFBPs-1 to -3 were assayed by Western ligand blot and their mRNA expression in the liver assayed by RNase protection assay in the hypothyroid populations: thyroidectomized and mercapto-1-methylimidazole (MMI)-treated neonates, and thyroidectomized adult rats at different periods after thyroidectomy. Serum concentrations of insulin, GH and IGF-I were increased in thyroidectomized neonates and decreased in the other populations. IGFBPs-1 and -2 increased $79 \%$ and $50 \%$ respectively in thyroidectomized neonatal rats compared with control at 15 days after thyroidectomy, whereas only IGFBP-2 increased (87\%) in MMI-treated neonates,
\end{abstract}

which had low serum insulin and GH compared with control on the same days. In thyroidectomized adult rats, IGFBPs-1 and -2 decreased 60\% compared with controls on all days studied. Furthermore, when streptozotocin was administered to thyroidectomized neonates and insulin was given to thyroidectomized adult rats to restore insulin to control values in both groups, a differential regulation was found for IGFBPs-1 and -2 . The transcriptionally induced decrease in IGFBP-3 (20-25\% compared with control in neonates and $50 \%$ in adult rats), however, seemed to be regulated by GH and IGF-I. The similarity of changes in IGFBPs found in hypothyroid, undernourished and streptozotocin-induced diabetic neonatal rats suggests that the regulatory effect of insulin or $\mathrm{GH}$ on the IGFBPs requires the reduced biologically active thyroid hormone that is found in these three populations. Journal of Endocrinology (2002) 172, 363-373

\section{Introduction}

The insulin-like growth factors (IGFs) are growthpromoting peptides that share significant structural homology with insulin. Unlike insulin, IGFs circulate in plasma complexed to a family of binding proteins (IGFBPs), of which only six have been cloned and sequenced (Rajaran et al. 1997).

Serum IGFBPs have been proposed to regulate the biological activities of the IGFs and also to have IGFindependent metabolic actions (Lewitt \& Baxter 1991, Rajaran et al. 1997). The hypothyroid state disturbs the ontogenic patterns of expression of serum IGF-II and the $30 \mathrm{kDa}$ complex of IGFBPs in the fetal period and of serum IGF-I and IGFBP-3 in adults (Donovan et al. 1989, Gallo et al. 1991, Näntö-Salonen et al. 1991, Rivero et al. 1995). In adult animals, plasma IGF-I and IGFBPs are mainly synthesized and secreted by the liver in response to stimulation by growth hormone (GH). Nevertheless, although thyroid hormone transcriptionally regulates $\mathrm{GH}$ gene expression (Evans et al. 1982), not all the effects of thyroid hormone on the IGFs system are GH-mediated (Ikeda et al. 1989, Näntö-Salonen et al. 1993). Low plasma IGF-I and reduced IGF bioactivity have been reported in hypothyroid patients, whereas high plasma IGF-I concentrations and low bioactivity (Miell et al. 1993) have been observed in hyperthyroid patients. Similar changes have been described in rats (Burstein et al. 1979), and a decrease in hepatic IGF-I mRNA expression has been reported in experimental hypothyroid animals (Harakawa et al. 1990). In addition, thyroid status is intimately involved in the regulation of glucose and insulin homeostasis (Lenzen \& Bailey 1984), and reduced IGF-I has been widely reported in experimental models of undernutrition and diabetes (Rivero et al. 1995, Goya et al. 1996, 1999), because the rates of synthesis and secretion of IGF-I/IGFBPs depend also upon the availability of adequate nutrient intake (Rosenfeld et al. 1990, Clemmons \& Underwood 1991, Thissen et al. 1994, Jones \& Clemmons 1995, Rajaran et al. 1997). Furthermore, a decrease in the biologically 
active thyroid hormone $\left(\mathrm{T}_{3}\right)$, as occurs in hypothyroidism, was found in undernourished and diabetic rats; this results from a diminished type I 5 '-deiodinase activity in the liver (Wartofsky \& Burman 1982). All these observations enhance interest in the study of the interaction between thyroid hormones and the IGF/IGFBP system.

Changes in plasma IGFBPs have been reported in hypothyroid conditions (Rodríguez-Arnao et al. 1994), and the expression of IGFBPs in hypothyroidism differs with age (Näntö-Salonen \& Rosenfeld 1992). In concert with this, we have recently reported (Ramos et al. 2001) that the $30 \mathrm{kDa}$ complex of serum IGFBPs, the most abundant during immaturity, increases in neonatal thyroidectomized rats compared with controls, and decreases in adult thyroidectomized rats, whereas IGFBP-3, the main IGFBP in adult mammals, decreases after thyroidectomy in both neonatal and adult stages, although these studies were carried out only at 15 days after thyroidectomy. There are few reports studying the changes in serum IGFBPs induced by thyroid disorders and even fewer on the potential regulation by insulin and $\mathrm{GH}$ in the hypothyroid condition. In an experimental model of hypothyroidism induced by thyroidectomy in three different groups of rats - neonatal, weaned and adult (Ramos et al. 1998) - we established that, during the neonatal period, the effects of thyroid hormones on IGF-I synthesis and secretion are mediated by insulin, whereas GH mediates the thyroid actions in adulthood. Conclusions obtained from these previous studies demonstrated that serum concentrations of insulin, GH and IGF-I in mercapto-1-methylimidazole (MMI)-treated neonatal rats differ from those in thyroidectomized rats, being increased compared with controls in thyroidectomized neonates and decreased in MMI-hypothyroid rats (Ramos et al. 1998) and, therefore, it seemed reasonable to suppose that these hormonal changes could also influence the regulation of IGFBPs in hypothyroid populations during the neonatal period. To investigate this possibility, a parallel study was carried out in bigger groups of rats under similar conditions, to measure plasma concentrations and liver expression of IGFBPs mRNA. Neonatal and adult rats were killed at 5,10 and 15 days after thyroidectomy in order to study the time-course of the effects of thyroxine $\left(\mathrm{T}_{4}\right)$ deprivation. In addition, to investigate the effect of insulin on the above parameters, thyroidectomized neonatal rats with high insulinemia were treated with streptozotocin (STZ), and thyroidectomized adult rats with low insulinemia were treated with insulin. Finally, within the neonatal population a third group of non-thyroidectomized MMI-treated neonatal rats was analyzed, because these animals differ from thyroidectomized counterparts with respect to their serum concentration of insulin (Ramos et al. 1998).

Therefore, the three aims of this study were: (1) to compare alterations in the IGFBPs in two hypothyroid neonatal populations, thyroidectomized and MMI-treated, which show a similar reduction in circulating thyroid hormones but different changes in plasma insulin, $\mathrm{GH}$ and IGF-I concentrations, in order to investigate whether insulin mediates the regulation of IGFBPs by thyroid hormones in neonatal animals, as it does that of IGF-I (Ramos et al. 1998) - which is an important consideration in the selection of an appropriate model of neonatal hypothyroidism; (2) to study whether the time elapsed after thyroidectomy plays a part in the changes in IGFBPs observed; and (3) to compare the regulation that hypothyroidism exerts on the three major serum IGFBPs (IGFBP-1, -2 and -3) in neonatal and adult rats with that observed in other groups that also have reduced plasma $\mathrm{T}_{3}$, such as undernourished and diabetic populations.

\section{Material and Methods}

\section{Materials}

MMI was obtained from Sigma Chemical Co. (St Louis, MO, USA). Streptozotocin was a kind gift of Upjohn Co. (Kalamazoo, MI, USA).

\section{Animals}

Wistar rats bred in our laboratory under conditions of controlled temperature and an artificial light/darkness cycle (lights on 0600-1800 h) were used throughout the study. Females were caged with males and mating was confirmed by the presence of spermatozoa in a vaginal smear. Each dam was housed individually from the 14th day of pregnancy. After birth, the number of pups in each litter was standardized to eight, and males and females were used in equal numbers. Animals were fed a standard laboratory diet (19 g protein, $56 \mathrm{~g}$ carbohydrate, $3.5 \mathrm{~g}$ lipid and $4.5 \mathrm{~g}$ cellulose $/ 100 \mathrm{~g}$ plus $12 \%$ humidity and salt and vitamin mixtures; Panlab, Barcelona, Spain) that was available ad libitum. In order to investigate whether food intake was reduced in hypothyroid animals, the stomach milk contents of thyroidectomized, MMI-hypothyroid and control neonates and the fodder intake of thyroidectomized and control adult rats were measured. Water was available ad libitum. Thyroidectomy was performed with the animal under ether anesthesia; control rats were sham operated. Although no signs of calcium deficiency were observed in the rats at any stage, total calcium concentration was measured in serum using the o-cresolphthalein complexone kit (Biomerieux, Marcy-l'Etoile, France) and no significant differences between control and thyroidectomized sera were found in neonatal and adult rats. However, a possible undetected hypocalcemia from potential loss of the parathyroid glands after thyroidectomy was prevented by addition of $1 \%$ calcium lactate to the drinking water of experimental and control rats. Animals were weighed daily. Blood was 


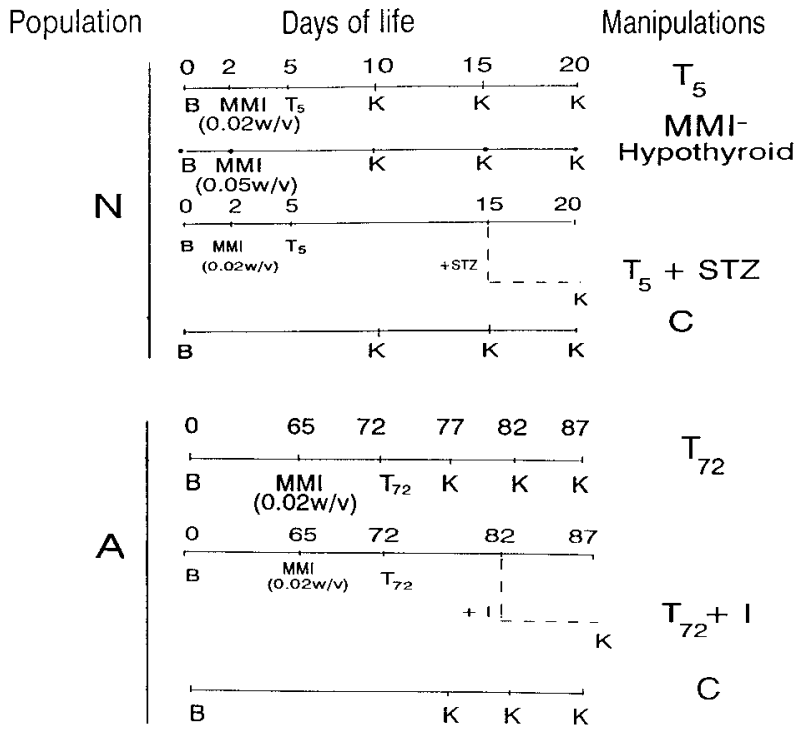

Figure 1 Summary of the experimental model. Two populations of rats were used: neonatal $(\mathrm{N})$ and adult $(\mathrm{A})$ rats. Neonatal rats were divided into four groups. Thyroidectomized rats $\left(\mathrm{T}_{5}\right)$ received mercapto-1-methylimidazole (MMI) $(0.02 \% \mathrm{w} / \mathrm{v}$ through milk) from day 2 after birth (B), were thyroidectomized on day 5 of life, and killed $(\mathrm{K})$ at 10, 15 or 20 days of life. MMI-hypothyroid rats (MMI) received only MMI $(0.05 \% \mathrm{w} / \mathrm{v})$ from day 2 after birth and were killed at 10,15 or 20 days of life. $T_{5}+S T Z$ rats, thyroidectomized as above, were given STZ on day 15 to suppress insulin secretion, and killed at 20 days. Control rats (C) were sham operated, and killed at 10, 15 or 20 days of life. Adult rats were divided into three groups. Thyroidectomized rats $\left(\mathrm{T}_{72}\right)$ received $0.02 \% \mathrm{w} / \mathrm{v}$ MMI from 65 days of life, were thyroidectomized at 72 days, and killed at 77,82 or 87 days of life. $T_{72}$ insulin rats $\left(\mathrm{T}_{72}+\mathrm{I}\right)$, thyroidectomized as above, were treated daily with insulin from day 82 of life, and killed at 87 days of life. Control rats (C) were killed at 77,82 or 87 days of life.

harvested from the trunk after the animal had been decapitated. All rats were killed at $1000 \mathrm{~h}$. Blood samples were allowed to clot on ice for $30 \mathrm{~min}$, and serum was separated and stored at $-80{ }^{\circ} \mathrm{C}$ until required for assay. Livers were frozen in liquid $\mathrm{N}_{2}$ upon removal for RNA extraction. European Community regulations for the use of animals as experimental models and other scientific purposes were followed. All experiments were conducted in accordance with the principles and procedures outlined in the National Institutes of Health (NIH; Bethesda, MD, USA) guide for the care and use of experimental animals.

\section{Experimental model}

Figure 1 depicts the experimental model. Two populations of rats were analyzed: neonatal and adult.

Neonatal rats were divided into four groups. Thyroidectomized $\left(T_{5}\right)$ rats received MMI $(0.02 \% \mathrm{w} / \mathrm{v}$ added to the drinking water of the mother) from day 2 of life; they were thyroidectomized on day 5 and killed on day 10, 15 or 20 of life (5,10 or 15 days after thyroidectomy). MMI was given from day 2 of life to ensure that $T_{3}$ and $T_{4}$ were adequately reduced, and to produce thyroid hyperplasia in order to facilitate thyroid gland withdrawal in 5-day-old neonates. MMI-hypothyroid rats were made hypothyroid from day 2 of life by MMI $(0 \cdot 05 \% \mathrm{w} / \mathrm{v}$ added to the drinking water of the mother) and were killed on day 10 , 15 or 20 of life. The dose of MMI was increased in the MMI-hypothyroid rats to provoke a degree of hypothyroidism similar to that in the thyroidectomized group; these dosages of MMI had previously been assayed to ensure the desired degree of hypothyroidism. $T_{5}+S T Z$ treated rats received $0.02 \% \mathrm{w} / \mathrm{v}$ MMI added to the drinking water from day 2 of life and were thyroidectomized on day 5 of life. In order to suppress insulin secretion, they were injected intraperitoneally with STZ (70 mg/kg body weight) in $0.05 \mathrm{M}$ citrate buffer $\mathrm{pH} 4.5$ on day 15 of life and killed on day 20 of life. The suppression of insulin secretion was confirmed 3 days later by the determination of glycemia and insulinemia. Control rats were sham operated.

Adult rats were divided into three groups. Thyroidectomized $\left(T_{72}\right)$ rats received $0.02 \% \mathrm{w} / \mathrm{v}$ MMI added to the drinking water from day 65 and were thyroidectomized on day 72 , then killed on day 77,82 or 87 of life (5,10 or 15 days after thyroidectomy) together with their controls. $T_{72}+$ insulin rats $(\mathrm{T}+\mathrm{I})$ received $0.02 \% \mathrm{w} / \mathrm{v}$ MMI added to the drinking water from day 65 of life, were thyroidectomized at 72 days, then treated subcutaneously with 3 IU/100 g body weight daily of Lente insulin (porcine-bovine) in two doses (given at 0900 and $1800 \mathrm{~h}$ ) starting at 82 days of life, and were killed on day 87. Glycemia and insulinemia were measured in order to assess insulin function. Control rats were killed on day 87 of life.

Some samples of the above populations had been used previously (Ramos et al. 1998), but the populations were enlarged for the present study. Rats were killed 5, 10 or 15 days after thyroidectomy in order to investigate the potential time-course of the effect of thyroid deprivation on the changes in IGFBPs.

\section{Iodination of IGF-II}

Iodine-125-labeled IGF-II was used as a radioactive probe for detection of IGFBPs in the westerm ligand blots. IGF-II was used instead of IGF-I because the former gives a better signal. Recombinant human IGF-II (Boehringer Mannheim, Leverkusen, Germany) was used for iodination. The specific activity achieved with this method was approximately $90-175 \mu \mathrm{Ci} / \mu \mathrm{g}$. $\mathrm{Na}^{125} \mathrm{I}$ was obtained from Amersham (Amersham Iberica SA, Madrid, Spain). Recombinant human IGF-II was labeled by a modified chloramine T method (Rivero et al. 1995). 


\section{Western ligand blotting}

Western ligand blots were performed as described previously (Rivero et al. 1995). After electrotransference of the blots to nitrocellulose, the membranes were incubated with ${ }^{125}$ I-labeled IGF-II $\left(10^{6}\right.$ c.p.m. $)$ for $20 \mathrm{~h}$ at $4{ }^{\circ} \mathrm{C}$ and autoradiographed against Hyperfilm MP between intensifier screens at $-70{ }^{\circ} \mathrm{C}$. Exposure times varied according to the signal obtained.

Autoradiographs were quantified by two-dimensional densitometry using a Personal Densitometer (Molecular Dynamics, Sunnyvale, CA, USA). Hyperfilm-MP autoradiography film was obtained from Amersham.

\section{Western immunoblotting}

Western immunoblots for enhanced chemiluminescence (ECL) were used for neonatal rats. The low serum concentration of $30 \mathrm{kDa}$ IGFBPs in thyroidectomized adult rats prevented their determination by ECL, when goat polyclonal anti-rat IGFBP-1 and -2 ready for ECL were used. Western immunoblots for ECL were performed on polyvinylidene fluoride (PVDF) immobilon-P membranes (Millipore, Madrid, Spain). Membranes were incubated with a 1:100 dilution (as suggested by the manufacturer, Santa Cruz Biotechnology, Quimigranel, Madrid, Spain) of affinity-purified goat polyclonal anti-rat IGFBP-1 or rat IGFBP-2 and then with a 1:1000 dilution of anti-goat $\mathrm{IgG}-$ horseradish peroxidase. Antigenantibody complexes were detected after subjection to an ECL assay (hyperfilm ECL, Amersham). A BLAST programmed search had been carried out by the manufacturer, Santa Cruz Biotechnology, to determine specificity and cross-reactivity of antibodies created against peptides of 15-20 amino acids, in order to achieve high specificity and very limited cross-reactivity.

\section{Preparation of RNA}

Total RNA was prepared by homogenization of livers in guanidinium thiocyanate as originally described (Rivero et al. 1995, Ramos et al. 1998). Samples were electrophoresed through $1 \%$ agarose, $2 \cdot 2 \mathrm{M}$ formaldehyde gels and stained with ethidium bromide in order to visualize the $28 \mathrm{~S}$ and $18 \mathrm{~S}$ ribosomal RNA and thereby confirm the integrity of the RNA. pT7 RNA 18S antisense control template (Ambion Inc., Austin, TX, USA) was used for lane loading control.

\section{Riboprobes}

Rat IGFBPs-1 to -3 and S18 cDNAs were kindly provided by Drs C T Roberts Jr and D LeRoith (NIH, Bethesda, MD, USA). Riboprobe Gemini II Core System (Promega Corporation, Madison, WI, USA) was used for the generation of RNA probes. Rat IGFBP-1 cDNA, ligated into a pGEM-3 plasmid, was linearized with HindIII and incubated with T7 RNA polymerase to generate an antisense riboprobe that recognizes two fragments, of 300 and 700 bases. Rat IGFBP-2 cDNA, ligated into a pGEM-4Z (Promega Biotech, Madison, WI, USA) plasmid, was linearized with HindIII and incubated with SP6 RN polymerase to generate a 550 base antisense riboprobe devoid of pGEM-4Z complementary sequences. Rat IGFBP-3 cDNA, ligated into a pGEM-4Z plasmid, was linearized with Acc I, and use was made of T7 RNA polymerase to generate a 343 base antisense riboprobe. S18 cDNA was incubated with T7 RNA polymerase to produce a 109 nucleotide runoff transcript, 80 nucleotides of which are complementary to human $18 \mathrm{~S}$ ribosomal RNA. The above riboprobes were synthesized with $\left[{ }^{32} \mathrm{P}\right] \mathrm{UTP}$, purchased from ICN (Nuclear Iberica SA, Madrid, Spain).

\section{Solution hybridization/RNAse protection assay}

Solution hybridization/RNAse protection assay was performed as previously described (Goya et al. 1996, Ramos et al. 1998). Autoradiography was performed at $-70{ }^{\circ} \mathrm{C}$ against a Hyperfilm MP film between intensifying screens. Bands representing protected probe fragments were quantified using a Molecular Dynamics scanning densitometer and accompanying software.

\section{Statistical analysis}

All data are presented as means \pm S.D. Statistical comparisons were performed by one-way analysis of variance, followed by the protected least significant difference test (Rivero et al. 1995, Goya et al. 1996).

\section{Results}

Food intake and hormonal profiles in MMI-treated and thyroidectomized neonatal rats before and after STZ treatment

It is shown in Table 1 that food intake, as measured by the milk content in the stomach, was similar in thyroidectomized and control neonates, but was decreased in MMI-hypothyroid rats compared with controls.

In the same experimental models of neonatal hypothyroidism, it was reported that plasma insulin, plasma and pituitary GH and IGF-I were increased in thyroidectomized neonates and decreased in MMIhypothyroid neonates, compared with controls (Ramos et al. 1998). For the present study, the same rat populations were enlarged. The results were similar to those previously reported; therefore, absolute values of plasma and pituitary $\mathrm{GH}$ and plasma insulin are not shown in the present paper. The same applies to data for body weight and serum $T_{3}$ and $\mathrm{T}_{4}$, which are decreased both in thyroidectomized and 
Table 1 Body weight and milk stomach content in thyroidectomized $\left(\mathrm{T}_{5}\right)$, MMI-hypothyroid and control $(C)$ neonatal rats and body weight and fodder intake of thyroidectomized $\left(\mathrm{T}_{72}\right)$ and control $(\mathrm{C})$ adult rats

\begin{tabular}{|c|c|c|c|}
\hline & \multicolumn{3}{|c|}{ Neonates (20 days old) } \\
\hline & $\mathrm{T}_{5}$ & $\mathrm{C}$ & MMI-hypothyroid \\
\hline \multirow{4}{*}{$\begin{array}{l}\text { Body weight }(\mathrm{g}) \\
\text { Milk stomach content (g) }\end{array}$} & $28 \cdot 55 \pm 3 \cdot 32^{*}$ & $54.93 \pm 1.93$ & $31 \cdot 5 \pm 3 \cdot 0^{*}$ \\
\hline & $0.63 \pm 0 \cdot 2$ & $0 \cdot 85 \pm 0 \cdot 22$ & $0 \cdot 56 \pm 0 \cdot 32^{*}$ \\
\hline & \multicolumn{3}{|c|}{ Adults (87 days old) } \\
\hline & $\mathrm{T}_{72}$ & $\mathrm{C}$ & \\
\hline Body weight (g) & $188 \cdot 90 \pm 13 \cdot 11^{*}$ & $317 \cdot 80 \pm 8 \cdot 54$ & \\
\hline Fodder intake (g) & $24 \cdot 92 \pm 1 \cdot 84^{*}$ & $49 \cdot 77 \pm 1 \cdot 39$ & \\
\hline
\end{tabular}

${ }^{*} P<0.05$ relative to control rats. MMI, mercapto-1-methylimidazole.

MMI-hypothyroid neonates compared with controls and remain unchanged after STZ treatment. These data have been reported previously (Ramos et al. 1998).

Food intake and hormonal profiles in thyroidectomized adult rats before and after insulin treatment

Table 1 shows that food intake in thyroidectomized adult rats was decreased compared with that in controls.

In the same experimental models of adult hypothyroidism, it was reported that body weight, blood glucose, plasma insulin, $\mathrm{T}_{3}$ and $\mathrm{T}_{4}$, pituitary $\mathrm{GH}$ and serum IGF-I were decreased in thyroidectomized rats compared with controls, and insulin treatment of thyroidectomized rats led to recovery only in body weight and plasma insulin (Ramos et al. 1998). These results have been confirmed in the present study with enlarged populations and, as with neonatal rats, absolute values are not shown.

Serum IGFBPs-1, to -3 and liver expression of IGFBPs-1 and $-2 m R N A$ in MMI-treated hypothyroid and thyroidectomized neonatal rats before and after STZ treatment and in thyroidectomized adult rats before and after insulin treatment

Hypothyroid neonates Figure 2 shows the decreased IGFBP-3 (45 kDa) and increased low molecular weight (30 kDa) IGFBPs (IGFBPs-1 and -2) in serum of neonatal rats killed 5,10 or 15 days after thyroidectomy $(10,15$ and 20 days of life), and in hypothyroid rats treated with MMI, as compared with controls. Non-thyroidectomized hypothyroid rats (i.e. those treated with MMI) showed a greater increase in serum $30 \mathrm{kDa}$ IGFBPs than did thyroidectomized rats (data not shown), and specific Western immunoblots showed an increase in IGFBPs-1 (79\%) and $-2(50 \%)$ in thyroidectomized rats compared with controls at 20 days of life, whereas IGFBP-1 decreased (16\%) and IGFBP-2 increased (87\%) in MMI-hypothyroid rats compared with controls at 20 days of life (Fig. 2). A slight increase in the intensity of changes in the $30 \mathrm{kDa}$ complex was observed in the neonatal group from day 5 to day 15 after thyroidectomy.

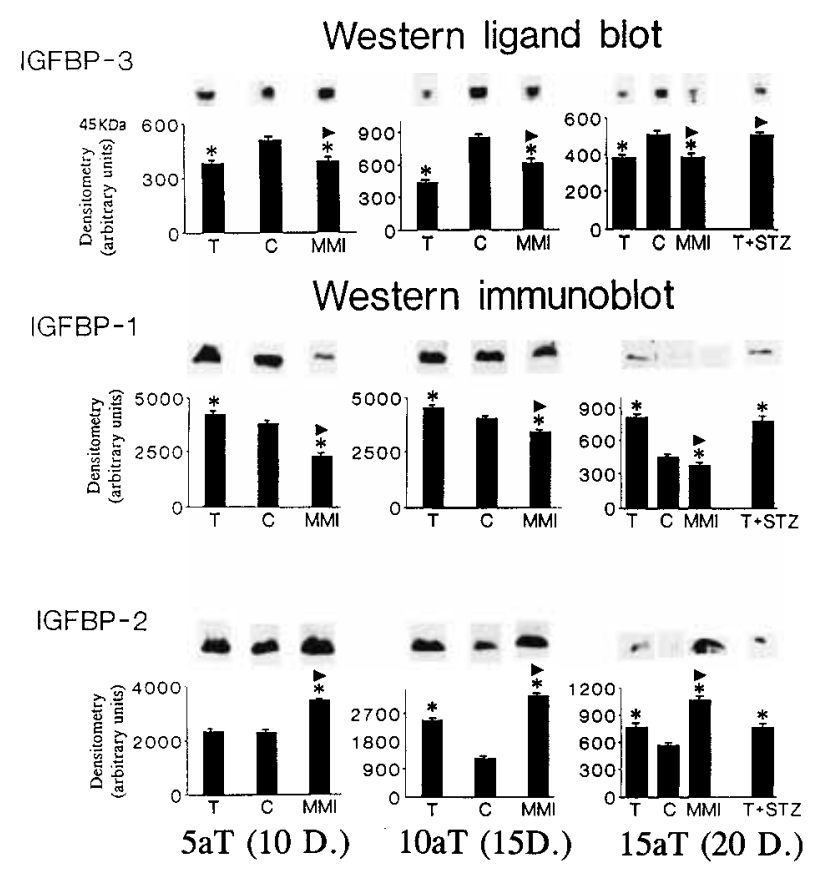

Figure 2 Western ligand blot of serum IGFBP-3 and Western immunoblot of serum IGFBP-1 and IGFBP-2 in neonatal rats (for descriptions of populations, see Methods and legend to Fig. 1). Representative bands are shown. Densitometric quantification (mean \pm S.D.) of the bands from four experiments with two samples run in each experiment (i.e. 8 animals analyzed per condition) is shown below the bands. ${ }^{*} P<0 \cdot 05$ relative to control rats; arrowhead, $P<0.05$ relative to thyroidectomized rats. aT, after thyroidectomy; D., days. 

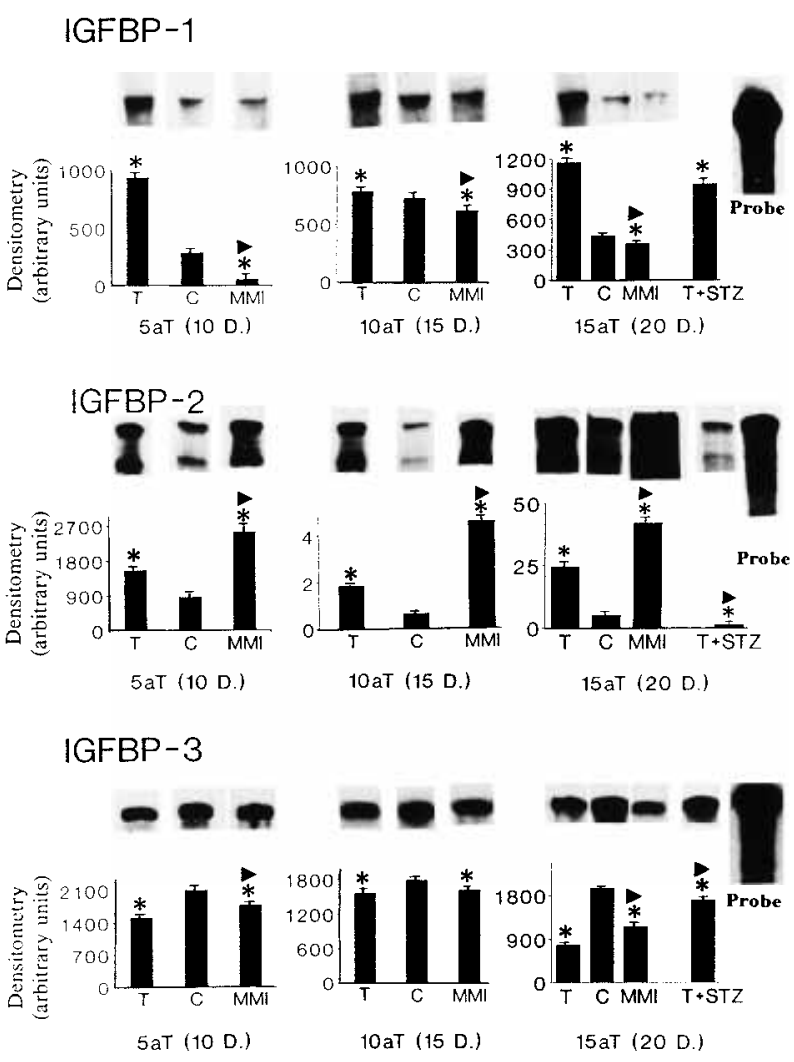

Figure 3 RNase protection assay of liver expression of IGFBPs-1 to -3 mRNA in neonatal rats. Rats thyroidectomized on day 5 of life $(\mathrm{T})$, control rats $(\mathrm{C})$ and rats treated with $\mathrm{MMI}(0.05 \% \mathrm{w} / \mathrm{v}$; $\mathrm{MMI}$ ) were killed 5, 10 or 15 days after thyroidectomy (aT), at 10, 15 or 20 days of life (D.). Expression of IGFBPs- 1 to -3 transcripts mRNA was determined by RNase protection assay. Representative bands are shown. Densitometric quantification (mean \pm S.D.) of the bands from four experiments with three samples run in each experiment (i.e. 12 animals analyzed per condition) is shown below the bands. ${ }^{*} P<0.05$ relative to control rats; arrowhead, $P<0.05$ relative to thyroidectomized rats.

Expression of IGFBPs-1 and -2 mRNA was found to be increased in the liver of thyroidectomized neonatal rats compared with that in controls; however, a decrease in the expression of IGFBP-1 mRNA and an increase (greater than that observed in thyroidectomized rats) in that of IGFBP-2 were found in the liver of MMI-treated hypothyroid rats as compared with controls (Fig. 3). These results confirm those obtained by Western immunoblot (Fig. 2) and show that the increase in serum $30 \mathrm{kDa}$ IGFBPs in thyroidectomized neonatal rats seems to be caused by an increase in both IGFBP-1 and -2 , whereas in MMI-treated rats it appears to be caused only by increased concentrations of IGFBP-2. Overall, increased serum concentrations and liver expression of IGFBPs-1 and -2 mRNA were observed in thyroidectomized neonatal rats, whereas IGFBP-2 mRNA was increased and IGFBP-1 mRNA was decreased in MMI-treated rats,

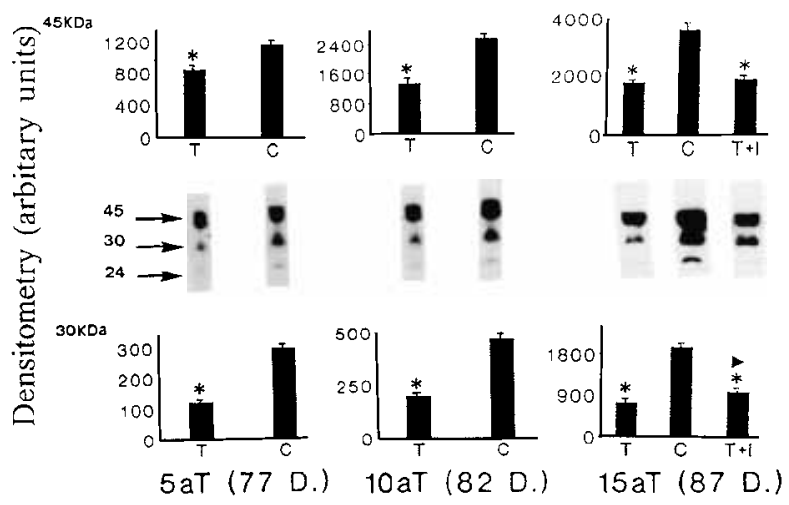

Figure 4 Western ligand blot analysis of adult rat serum IGFBPs. Thyroidectomized rats (T) were killed 5, 10 or 15 days after thyroidectomy (aT), at 77,82 or 87 days of life respectively (D.), and rats thyroidectomized at 72 days but treated with insulin from day $82(\mathrm{~T}+\mathrm{I})$ were killed at 87 days. The approximate molecular masses $\left(\times 10^{3}\right)$ are shown on the left. Representative bands are shown. Densitometric quantification (mean \pm S.D.) of the bands from four experiments with two samples run in each experiment (i.e. 8 animals analyzed per condition) is shown below the bands. ${ }^{\star} P<0.05$ relative to control rats; arrowhead, $P<0 \cdot 05$ relative to thyroidectomized rats.

suggesting a transcriptional regulation for both IGFBPs in thyroidectomized and MMI-treated neonatal rats.

When insulin secretion was blunted by STZ treatment, the $30 \mathrm{kDa}$ complex of IGFBPs remained increased over that of controls (data not shown). Western immunoblot assay showed no differences in IGFBPs- 1 and -2 between thyroidectomized and group thyroidectomized+STZtreated rats (Fig. 2), indicating that serum concentrations of IGFBPs-1 and -2 remained basically unchanged in thyroidectomized neonatal rats after STZ treatment. However, liver expression of IGFBP-2 mRNA was greatly decreased in thyroidectomized+STZ-treated rats compared with that in thyroidectomized animals, whereas no change was observed in liver expression of IGFBP-1 mRNA, which remained above control values after STZ treatment. The STZ-induced decrease in liver expression of IGFBP-2 mRNA observed in these populations differs from the unchanged serum concentrations and suggests the absence of transcriptional regulation for this IGFBP in these conditions.

Thyroidectomized adult rats Figure 4 shows that circulating concentrations of IGFBP-3 and $30 \mathrm{kDa}$ IGFBPs decreased in thyroidectomized rats compared with those in control adult rats, at 5, 10 and 15 days after thyroidectomy.

Liver expression of IGFBP-1 mRNA was decreased compared with controls at all stages $(5,10$ and 15 days after thyroidectomy) in adult animals (Figs 5 and 6). However, 


\section{ADULTS}

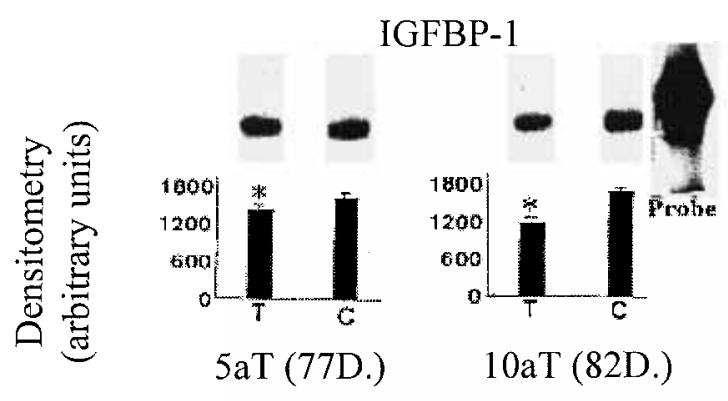

\section{IGFBP-2}

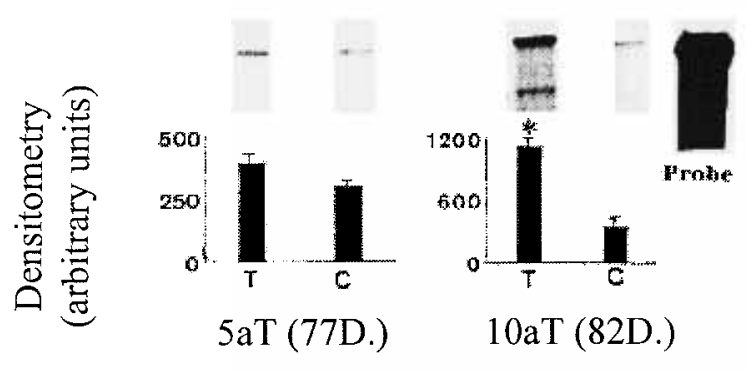

\section{IGFBP-3}
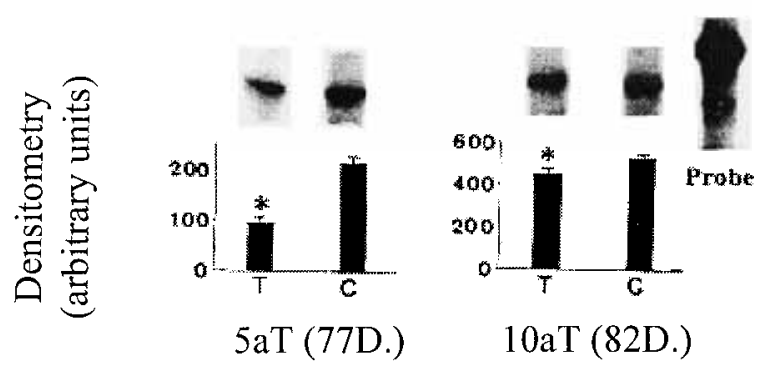

Figure 5 RNase protection assay of liver IGFBPs- 1 to -3 transcripts in adult rats. Rats thyroidectomized at 72 days of life $(\mathrm{T})$ and control rats (C) were killed 5 or 10 days (D.) after thyroidectomy (aT), corresponding to 77 or 82 days of life. Representative bands are shown. Densitometric quantification (mean \pm S.D.) of the bands from four experiments with three samples run in each experiment (i.e. 12 animals analyzed per condition) is shown below the bands. ${ }^{*} P<0.05$ relative to control rats.

liver expression of IGFBP-2 mRNA was increased compared with controls from 10 days after thyroidectomy onward in adults (Figs 5 and 6).

After insulin treatment, circulating $30 \mathrm{kDa}$ IGFBPs was slightly increased in adult rats compared with

\section{ADULTS}

\section{IGFBP-1}

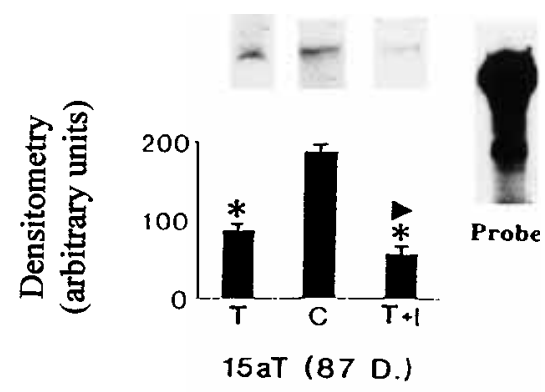

\section{IGFBP-2}

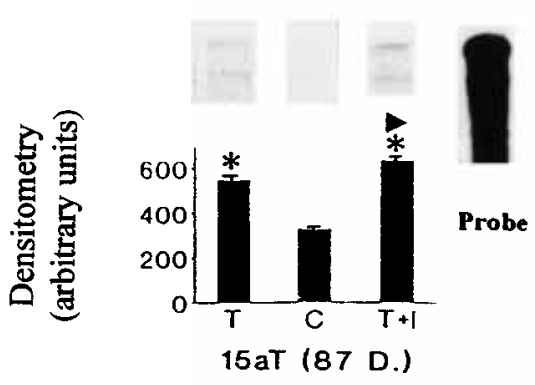

IGFBP-3
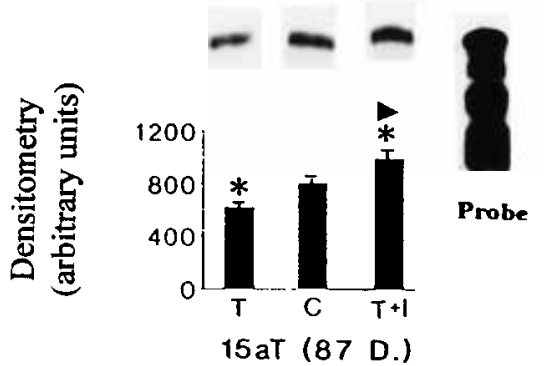

Figure 6 RNase protection assay of liver IGFBPs- 1 to -3 transcripts in adult rats. Rats were thyroidectomized at 72 days and killed 15 days after thyroidectomy (aT), at 87 days of life (T), or thyroidectomized at 72 days and treated with insulin from day 82 until killed on day $87(\mathrm{~T}+\mathrm{I})$. Representative bands are shown. Densitometric quantification (mean \pm S.D.) of the bands from four experiments with two samples run in each experiment (i.e. 8 animals analyzed per condition) is shown below the bands. ${ }^{\star} P<0.05$ relative to control rats $(C)$; arrowhead, $P<0 \cdot 05$ relative to thyroidectomized rats.

thyroidectomized animals, but the amounts remained less than those in controls (Fig. 4). Liver IGFBP-1 mRNA expression showed a slight reduction in thyroidectomized adults: IGFBP-1 mRNA expression barely changed and remained less than control values. Therefore, insulintreated adult rats showed parallel changes in both liver expression of IGFBP-1 mRNA and circulating 
concentrations of the $30 \mathrm{kDa}$ complex, suggesting a transcriptional regulation of IGFBP-1 (Figs 4 and 6).

Finally, insulin treatment in adults provoked a slight increase in the $30 \mathrm{kDa}$ complex in serum (Fig. 4), which was accompanied by a parallel increase in the liver expression of IGFBP-2 mRNA, but not of IGFBP-1 mRNA. In thyroidectomized adults, a decrease in liver IGFBP-1 mRNA and an increase in IGFBP-2 mRNA were observed (Fig. 6), and insulin treatment increased these values.

Serum concentrations and liver expression of IGFBP-3 $m R N A$ in MMI-hypothyroid and thyroidectomized neonatal rats before and after STZ treatment, and in thyroidectomized adult rats before and after insulin treatment

Hypothyroid neonates In concert with the decreased serum IGFBP-3 shown by Western ligand blot (Fig. 2: 20-25\% compared with controls in both hypothyroid populations), the reduced hepatic expression of IGFBP-3 mRNA found in both hypothyroid groups (thyroidectomized and MMI-treated) suggests a transcriptional regulation of this binding protein (Fig. 3).

When insulin secretion was blunted by STZ treatment in thyroidectomized neonates, in conditions of increased serum insulin and GH compared with control and MMItreated rats (Ramos et al. 1998), serum IGFBP-3 increased to reach control values (Fig. 3, group T+STZ). The increase in liver expression of IGFBP-3 mRNA in STZtreated thyroidectomized rats compared with that in thyroidectomized rats (Fig. 3) paralleled the increased serum concentration (Fig. 2).

Thyroidectomized adult rats Liver expression of IGFBP-3 mRNA was decreased compared with controls in thyroidectomized adult (Figs 5 and 6), in parallel with the circulating concentrations $(50 \%$ decrease compared with control in thyroidectomized adult rats; Fig. 4), suggesting a transcriptional regulation, as most of the serum IGFBP-3 originates in the liver. Insulin treatment 15 days after thyroidectomy did not provoke any change in circulating IGFBP-3 in adult rats (Fig. 4, group $\mathrm{T}+\mathrm{I})$. Insulin treatment increased liver expression of IGFBP-3 mRNA compared with that in thyroidectomized animals, reaching values slightly greater than those in control adults (Fig. 6). Parallel changes in liver gene expression and serum concentrations of IGFBP-3 after insulin treatment were not observed in adult rats.

\section{Discussion}

Regulation of IGFBPs-1 and -2

MMI has been used as a goitrogenic drug in most studies on the regulation of IGFs/IGFBPs in hypothyroid neonatal animals. Thyroidectomy is a non-pharmacological model for the induction of hypothyroidism. During the neonatal period, a similar reduction in circulating thyroid hormones has been observed in both thyroidectomized and MMItreated animals, but decreased serum IGF-I, insulin and GH have been reported in MMI-treated neonatal rats (Gallo et al. 1991, Näntö-Salonen et al. 1991, Näntö-Salonen \& Rosenfeld 1992), whereas the same parameters increase in thyroidectomized neonates (Ramos et al. 1998). These results agree with the reduced food intake observed in our MMI-hypothyroid rats but not in thyroidectomized neonates. Thus comparison of the changes in IGFBPs between these two neonatal models could demonstrate whether thyroid hormone deficiency evokes changes in IGFBPs, such as the specific increase in IGFBP-2 previously reported (Näntö-Salonen et al. 1991, Näntö-Salonen et al. 1993), or whether these changes result from variations in other factors, such as serum insulin and GH, which seem also to regulate IGF-I in hypothyroid neonatal rats (Ramos et al. 1998).

The most important IGFBPs during the neonatal period are IGFBPs-1 and -2 (Donovan et al. 1989, NäntöSalonen et al. 1991). The results for serum concentration and liver mRNA expression obtained in both experimental models during this period show that the increase in serum concentration of the $30 \mathrm{kDa}$ complex (IGFBPs-1 and -2 ) is due to increases in both IGFBPs- 1 and -2 in thyroidectomized neonates but only in IGFBP-2 in MMItreated rats. The increase in IGFBP-2, therefore, is not only the result of a direct effect of thyroid hormone deprivation as has been reported (Näntö-Salonen et al. 1991), because IGFBP-2 is less increased in thyroidectomized neonates than in MMI-treated rats, whereas thyroid hormones are equally reduced in both groups (Ramos et al. 1998). In fact, the variations in serum IGFBPs-1 and IGFBP-2 between both hypothyroid models in neonates could have been caused by a different nutritional status, as the stomach milk content of MMIhypothyroid rats was decreased compared with that in controls, whereas the content in thyroidectomized neonates was similar to that in control neonates. The reduced food intake found in MMI-hypothyroid neonates could also be the cause of the decreased plasma insulin and $\mathrm{GH}$ observed in these animals. In addition, this fact suggests that the increase in IGFBP-2 in MMI-treated rats is modulated by the different circulating concentrations of insulin and GH found in thyroidectomized and MMItreated neonates. These differences in plasma insulin and $\mathrm{GH}$ observed between the two populations seem to indicate that the imbalance provoked by thyroid withdrawal in immature stages of the hypothalamic system increases plasma insulin and $\mathrm{GH}$, perhaps through adrenergic stimulation or glucocorticoid influence (Kitabchi et al. 1968); these two possibilities are currently being studied in hypothyroid neonatal rats in our laboratory. In addition, these differences also suggest a possible 
inhibitory effect of goitrogen drugs per se on serum insulin, as described previously (Jolin et al. 1970). All the above effects should be considered in future studies with this frequently utilized MMI experimental model.

Serum IGFBP-2 is increased in mild diabetes (Strasser-Vogel et al. 1995), similar to the low insulin and euglycemia found in MMI-treated rats, and this metabolic condition seems to have a very important role in the regulation of IGFBP-2 in conditions of $\mathrm{T}_{4}$ deficiency. Surprisingly, Western blot of serum and RNase protection assay of liver showed that IGFBP-1 increased in thyroidectomized neonates, which had high serum insulin, and decreased in MMI-treated rats, with low serum insulin, contrary to the previously shown insulindependent down-regulation of IGFBP-1 (Baxter \& Cowell 1987, Lewitt et al. 1994). However, it has also been reported that changes in IGFBP-1 in children may not be linked specifically to changes in insulin secretion (Cotterill et al. 1988, Smith et al. 1995), as can also be inferred from the findings in both the hypothyroid neonatal populations of rats described here. It is worth noting that insulin concentrations shown in these experiments are systemic, and the portal concentration of insulin was not measured in these rats. Nevertheless, the inhibiting effect of insulin on IGFBP-1, established in situations of severe diabetes in humans (Muñoz et al. 1996) and animals (Lewitt et al. 1994), has been observed in the thyroidectomized neonates given STZ, in which liver IGFBP-1 gene expression remained increased compared with that in controls, whereas liver expression of IGFBP-2 mRNA remained reduced. These results are in agreement with those found in diabetic neonatal rats (Rivero et al. 1995), in which the absence of insulin up-regulates IGFBP-1. In the longer term after STZ treatment, the diabetes-induced IGFBP-1 up-regulation would perhaps have been clearly observed in this group of neonatal rats.

The regulatory mechanism of both binding proteins of the $30 \mathrm{kDa}$ complex found in these neonatal rats seems to support the concept that IGFBP-1 is increased only in conditions of clear insulinopenia, such as diabetes mellitus (Strasser-Vogel et al. 1995), whereas IGFBP-2 increases in conditions of thyroid hormone deficiency, low insulin and euglycemia. The parallel changes in circulating concentrations of IGFBPs- 1 and -2 and liver expression of their mRNA found in both hypothyroid neonatal groups suggest a transcriptional regulation of these two proteins, as most of the circulating IGFBPs originate in the liver, although they can be synthesized and secreted by other organs. The linear regression analysis between serum data and liver mRNA expression data produced regression coefficients of $r=0.98$ for IGFBP-1 and $r=0.96$ for IGFBP-2, results that support the suggested transcriptional regulation of both IGFBPs.

In hypothyroid adult rats, despite the decrease in the circulating $30 \mathrm{kDa}$ complex, liver expression of IGFBP-2 mRNA increased, whereas that of IGFBP-1 decreased in hypothyroid adult rats at all stages studied. Thus, contrary to that of IGFBP-1, liver expression of IGFBP-2 mRNA increased in thyroidectomized adults and MMI-treated neonates - two conditions with a similar endocrine status of low serum insulin, $\mathrm{T}_{4}$ and IGF-I, euglycemia and reduced food intake (Table 1), as described in undernourished adult rats (Goya et al. 1999), which had decreased blood insulin, GH, $\mathrm{T}_{4}$ and IGF-I. It is worth mentioning that thyroidectomized adult rats showed a reduced food intake, suggesting that the decrease in insulin in thyroidectomized adults, as in MMI-hypothyroid neonates, could result from both thyroid function deficiency and food restriction and, in both populations, increases in IGFBP-2. Insulin treatment in thyroidectomized adult rats led to a slight increase in the serum $30 \mathrm{kDa}$ complex of IGFBPs, but the values remained less than those of control rats, indicating a minimal effect of the hormone at these stages of life. Therefore, the changes in the $30 \mathrm{kDa}$ complex reported in both neonatal and adult hypothyroid rats show that the well-established reverse correlation between insulin and IGFBP-1 can be observed only in conditions of considerably decreased insulin, whereas the liver mRNA expression of IGFBP-2 seems to be more sensitive to slight changes in insulin.

\section{Regulation of IGFBP-3}

Circulating concentration of IGFBP-3 and expression of its mRNA in liver, less abundant in immature stages, decreased in both hypothyroid neonatal populations, and increased without reaching control values after STZ treatment, as previously reported for diabetic neonatal rats (Rivero et al. 1995, Goya et al. 1996); this increase may be due to the increase found in serum GH (Ramos et al. 1998). Circulating IGFBP-3, the most abundant IGFBP in adult serum, was decreased in hypothyroid adult rats, indicating its dependence on GH and IGF-I, which were also reduced in these groups (Jones \& Clemmons 1995, Rajaran et al. 1997, Ramos et al. 1998). Hepatic expression of IGFBP-3 mRNA also decreased in the same populations at all ages studied, suggesting a transcriptional regulation in the liver, the main source of the serum IGFBP-3. This result in adult populations was supported by the results of linear regression analysis between serum data and liver mRNA expression data $(r=0 \cdot 99)$. Insulin treatment of thyroidectomized adult rats increased serum concentrations and liver expression of IGFBP-3 mRNA without evoking changes in serum GH (Ramos et al. 1998), but an increase in serum IGF-I has been reported in these rats after insulin treatment (Ramos et al. 1998). Moreover, insulin has been reported to up-regulate serum GH in insulin-deficient animals (González \& Jolin 1985); perhaps a longer treatment with insulin would be required to increase serum $\mathrm{GH}$. 
With respect to the goals proposed in this study, IGFBPs- 1 and -2 seem to be regulated in a specific and different manner in neonatal hypothyroid populations, depending on the serum concentrations of insulin, $\mathrm{GH}$ and IGF-I. Furthermore, the present results show that the changes in IGFBP-2 in hypothyroid neonatal rats do not seem to be modulated by a specific effect of thyroid hormone deprivation, contrary to what has been suggested to date (Näntö-Salonen et al. 1991). The present study revealed no changes in IGFBPs at different time-points after thyroidectomy, indicating that the duration of exposure to thyroid deprivation is not relevant to IGFBP regulation in the two populations studied. More complex mechanisms seem to regulate IGFBPs in hypothyroid neonatal and adult rats than those, insulin- and GH-mediated, suggested for IGF-I (Ramos et al. 1998).

Finally, this study demonstrates the resemblance of changes in IGFBPs between hypothyroid and undernourished populations and between thyroidectomized neonates treated with STZ and diabetic rats. This would indicate that IGFBPs seem to be regulated by insulin and $\mathrm{GH}$, but always in conditions of reduced biologically active thyroid hormones which, in undernourished and diabetic rats, are the result of inhibition of liver type I 5'-deiodinase activity (Wartofsky \& Burman 1982).

\section{Acknowledgements}

We are grateful to the National Hormone and Pituitary Program for the supply of immunoreactants for the determination of rat $\mathrm{GH}$, the Upjohn Co. for supplying streptozotocin, and Novo Nordisk Pharma SA for supplying Lente insulin. The authors thank especially Dr Morreale de Escobar and the members of her laboratory Socorro Durán, $M$ Jesús Presas for plasma $T_{3}$ and $T_{4}$ determination, and Susana Fajardo for her technical help. This work was supported by a grant from DGICYT (Ministerio de Educación y Ciencia) Spain (Ref.: PM970017) and a grant from Comunidad Autónoma de Madrid (CAM; Ref.: 08·50009/97). S Ramos was supported by a fellowship from Conserjería de Educación y Cultura from CAM.

\section{References}

Baxter RC \& Cowell CT 1987 Diurnal rhythm of growth hormone independent binding protein for insulin-like growth factors in human plasma. Journal of Clinical Endocrinology and Metabolism $\mathbf{6 5}$ 432-440.

Burstein PJ, Draznin B, Johnson CJ \& Schalch DS 1979 The effects of hypothyroidism on growth, serum growth hormone, the growth hormone dependent somatomedin, insulin-like growth factor, and its carrier protein in rats. Endocrinology 104 1107-1111.

Clemmons DR \& Underwood LE 1991 Nutritional regulation of IGF-I and IGF binding proteins. Annual Review of Nutrition 11 393-412.
Cotterill M, Cowell CT, Baxter RC, McNeil D \& Silink M 1988 Regulation of the growth hormone-independent growth factor binding protein in children. Journal of Clinical Endocrinology and Metabolism 67 882-887.

Donovan SM, Oh Y, Pham H \& Rosenfeld RG 1989 Ontogeny of the insulin-like growth factor binding proteins in the rat. Endocrinology 125 2621-2627.

Evans RM, Birnberg NC \& Rosenfeld MG 1982 Glucocorticoid and thyroid hormone transcriptionally regulate growth hormone gene expression. PNAS 79 7659-7663.

Gallo D, de Marchis M, Voci A \& Fugassa E 1991 Expression of hepatic mRNAs for insulin-like growth factors-I and -II during the development of hypothyroid rats. Journal of Endocrinology 131 367-372.

González C \& Jolin T 1985 Effect of streptozotocin diabetes and insulin replacement on growth hormone in rats. Journal of Endocrinological Investigation 8 7-11.

Goya L, Rivero F, Martín MA, Arahuetes R, Hernández ER \& Pascual-Leone AM 1996 Effects of refeeding of undernourished and insulin treatment of diabetic neonatal rats on IGF and IGFBP. American Journal of Physiology 271 E223-E231.

Goya L, Rivero F, Martín MA, Alvarez C, Ramos S, de la Puente A \& Pascual-Leone AM 1999 Liver mRNA expression of IGF-I and IGFBPs in adult undernourished diabetic rats. Life Science 64 2255-2271.

Harakawa S, Yamashita S \& Tobinaga T 1990 In vivo regulation of hepatic insulin like growth factor I mRNA with thyroid hormone. Endocrinology Japan 37 205-211.

Ikeda T, Fujiama K \& Takeuchi T 1989 Effect of thyroid hormone on somatomedin $\mathrm{C}$ release from perfused rat liver. Experientia $\mathbf{4 5}$ 170-180.

Jolin T, Morreale de Escobar G \& Escobar del Rey F 1970 Differential effects in the rat of thyroidectomy, propylthiouracil and other goitrogens on plasma insulin and thyroid weight. Endocrinology 87 99-111.

Jones JI \& Clemmons DR 1995 Insulin-like growth factors and their binding proteins: biological actions. Endocrine Reviews 16 3-34.

Kitabchi AE, Buchanan KD, Vance JE \& Wiliams RH 1968 Effect of adrenocorticotropin and glucocorticoids on insulin secretion. Journal of Clinical Endocrinology and Metabolism 28 1479-1490.

Lenzen S \& Bailey CJ 1984 Thyroid hormones, gonadal and adrenocortical steroids and the function of the islets of Langerhans. Endocrine Reviews 5 411-421.

Lewitt MS \& Baxter RC 1991 Insulin-like growth factor binding protein-1: a role in glucose counterregulation? Molecular and Cellular Endocrinology 79 C147-C152.

Lewitt MS, Saunders H, Phyual JL \& Baxter RC 1994 Regulation of insulin-like growth factor-binding protein-1 in rat serum. Diabetes 43 232-239.

Miell JP, Taylor AM, Zini M, Maheshwari HG, Ross RJM \& Valcavi R 1993 Effects of hypothyroidism and hyperthyroidism on insulin-like growth factors (IGFs) and growth hormone and IGF binding proteins. Journal of Clinical Endocrinology and Metabolism 76 950-953.

Muñoz MT, Barrios V, Pozo J \& Argente J 1996 Insulin-like growth factor I, its binding proteins 1 and 3 , and growth hormone binding protein in children and adolescents with insulin dependent diabetes mellitus: clinical implications. Pediatric Research 39 992-998.

Näntö-Salonen K \& Rosenfeld RG 1992 Insulin-like growth factor binding protein expression in the hypothyroid rat is age dependent. Endocrinology 131 1489-1496.

Näntö-Salonen K, Glasscock GF \& Rosenfeld RG 1991 The effects of thyroid hormone on insulin like growth factor (IGF) and IGF-binding protein (IGFBP) expression in the neonatal rat: prolonged high expression of IGFBP-2 in methimazole-induced congenital hypothyroidism. Endocrinology 129 2563-2570. 
Nantö-Salonen K, Muller HL, Hoffman AR, Vu TH \& Rosenfeld RG 1993 Mechanism of thyroid hormone action on the insulin-like growth factor system: all thyroid hormone effects are not growth hormone mediated. Endocrinology 132 781-788.

Rajaran S, Baylink DJ \& Mohan S 1997 Insulin-like growth factorbinding proteins in serum and other biological fluids: regulation and functions. Endocrine Reviews 18 801-831.

Ramos S, Goya L, Alvarez C \& Pascual-Leone AM 1998 Mechanism of hypothyroidism action on insulin-like growth factor-I and -II from neonatal to adult rats: insulin mediates thyroid hormone effects in the neonatal period. Endocrinology 139 4782-4792.

Ramos S, Goya L, Alvarez C, Martín MA \& Pascual-Leone AM 2001 Effect of thyroxine administration on the IGFs/IGFBPs system in neonatal and adult thyroidectomized rats. Journal of Endocrinology $169111-122$

Rivero F, Goya L, Aláez C \& Pascual-Leone AM 1995 Effects of undernutrition and diabetes on serum and liver mRNA expression of IGFs and their binding proteins during rat development. Journal of Endocrinology 145 427-440.

Rodríguez-Arnao J, Miell J, Thomas M, McGregor AM \& Ros RJM 1994 Changes in hepatic insulin-like growth factor binding proteins $-1,-2$ and -3 mRNA levels in rats with altered thyroid status. Journal of Endocrinology 140 251-255.
Rosenfeld RG, Lamson G, Phan H, Oh Y, Conover Ch, De Leon DD, Donovan SM, Ocrant I \& Giudice L 1990 Insulin like growth factor-binding proteins. Recent Progress in Hormone Research 46 99-163.

Smith WJ, Underwood LE \& Clemmons DR 1995 Effects of caloric or protein restriction on insulin-like growth factor-I (IGF-I) and IGF-binding proteins in children and adults. Journal of Clinical Endocrinology and Metabolism 80 443-449.

Strasser-Vogel B, Blum WF, Past R, Kessler U, Hoeflich A, Meiler B \& Kiess W 1995 Insulin-like growth factor (IGF)-I and -II and IGF-binding proteins-1, $-2,-3$ in children and adolescents with diabetes mellitus: correlation with metabolic control and height attainment. Journal of Clinical Endocrinology and Metabolism $\mathbf{8 0}$ 1207-1213.

Thissen JP, Ketelslegers JM \& Underwood LE 1994 Nutritional regulation of the insulin-like growth factors. Endocrine Reviews $\mathbf{1 5}$ 80-103.

Wartofsky L \& Burman KD 1982 Alterations in thyroid function in patients with systemic illness: The euthyroid sick syndrome. Endocrine Reviews 3 164-217.

Received 11 September 2001 Accepted 26 October 2001 